Journal of Chromatography, 383 (1986) 69-76

Biomedical Applications

Elsevier Science Publishers B.V., Amsterdam - Printed in The Netherlands

CHROMBIO. 3323

\title{
DETERMINATION OF PLASMA TRIMETREXATE LEVELS USING GAS CHROMATOGRAPHY - MASS SPECTROMETRY WITH SELECTED-ION MONITORING
}

\author{
P.L. STETSON* \\ Department of Pharmacology, Upjohn Center for Clinical Pharmacology, University of \\ Michigan Medical School, Ann Arbor, MI 48109 (U.S.A.) \\ and \\ W.D. ENSMINGER
}

Departments of Pharmacology and Internal Medicine, Upjohn Center for Clinical Pharmacology, University of Michigan Medical School, Ann Arbor, MI 48109 (U.S.A.)

(First received October 23rd, 1985; revised manuscript received July 1st, 1986)

\section{SUMMARY}

Trimetrexate is a potent inhibitor of dihydrofolate reductase and has demonstrated significant antitumor activity against murine and human cell lines both in vitro and against several murine transplanted tumors. The importance of antifolate concentration and exposure time in determining toxic and therapeutic effects necessitates an assay of suitable sensitivity, accuracy and specifity for investigation of trimetrexate pharmacokinetics. This paper describes a gas chromatographic-mass spectrometric (GC-MS) procedure using selected-ion monitoring (SIM) for the determination of plasma trimetrexate levels. Using the $\mathrm{C}_{13}$ Bond-Elut extraction columns, the drug and internal standard are removed from plasma, derivatized to their bis(trimethylsilyl) derivatives and analysed by GC-SIM-MS. The reproducibility of the daily standard curves had coefficients of variation ranging from 4.9 to $11.4 \%$. The precision of the assay yielded a coefficient of variation ranging from 5.6 to $10.1 \%$, and the concentration means for the seeded control samples were found to be within -3.7 to $+0.7 \%$ of the theoretical values for trimetrexate. No interfering peaks have been observed in application of the procedure on patient samples. The minimum detectable level under the conditions described was $0.005-0.014 \mu M$ trimetrexate.

\section{INTRDDUCTION}

Trimetrexate, 2,4-diamino-5-methyl-6-[(3,4,5-trimethoxyanilino)methyl] quinazoline (TMQ), was originally synthesized by Elslager and Davoll [1]. It is a potent inhibitor of dihydrofolate reductase (DHFR) (5,6,7,8-tetrahydrofolate:NADP ${ }^{+}$oxidoreductase, EC 1.5.1.3) [2] and has demonstrated 
significant antitumor activity against murine and human cell lines both in vitro and against several murine transplanted tumors [3, 4] . TMQ is more lipophilic than the classical antifolate, methotrexate, and has demonstrated an increased uptake into neoplastic cells compared to methotrexate [5]. Also, TMQ's enhanced lipophilicity may afford it greater penetration into the central nervous system (CNS) and, therefore, greater efficacy than methotrexate against CNS neoplasms. Since TMQ does not utilize the reduced folate transport system in its entry into cells (as does methotrexate), it has been shown effective in vitro against a human lymphocytic leukemia cell line resistant to methotrexate by virtue of impaired drug transport [6] .

The importance of antifolate concentration and exposure time in determining toxic and therapeutic effects both in vitro and in vivo in experimental animal tumors has been established [7-10]. These investigators have shown that a cell-type dependent minimal concentration was needed to inhibit cell growth or DNA synthesis and that no additional benefit of cell kill (in leukemia L1210 cells) was obtained with higher antifolate (methotrexate) concentrations [9]. Studies in experimental animal systems have also shown that biological response to antifolates is determined by exposure time and is selective for individual tissues [11-13]. These findings suggest a therapeutic rationale for the prolonged infusion of TMQ at rigidly controlled dose rates which achieve steady-state TMQ plasma levels toxic to neoplastic cells but below the toxic threshold of bone marrow cells from that individual patient.

Such exacting therapy will require a complete understanding of the pharmacokinetics and pharmacodynamics of TMQ. This, in turn, necessitates the availability of accurate, sensitive and specific assay procedures for the drug in biological fluids. Previous methods for TMQ determination were based on either high-performance liquid chromatographic (HPLC) $[14,15]$ or DHFR inhibition $[14,16]$ techniques. Problems with sample TMQ recovery [14] were alleviated with the use of the $\mathrm{C}_{18}$ Bond-Elut system and resulted in a sensitive (0.05 $\mu M$ detection limit) and specific TMQ HPLC assay [15]. However, no internal or external standards were employed. The DHFR inhibition procedures are highly sensitive ( $0.005 \mu M$ TMQ detectability), but suffer from a lack of specificity, a 15-20\% variability and an extremely narrow range of linearity in the concentration-inhibition curve [16] . Most recently, a competitive protein binding assay for TMQ has been reported [17]. This method, although sensitive in the range of $0.002 \mu M$ TMQ, has not yet been fully characterized as to its TMQ specificity.

This paper describes a sensitive, specific and internally standardized assay procedure for the determination of plasma TMQ levels. The sample preparation utilizes the $\mathrm{C}_{18}$ Bond-Elut system [15], modified for optimal compatibility with subsequent chemical derivatization and gas chromatographic-mass spectrometric (GC-MS) procedure using selected-ion monitoring (SIM).

EXPERIMENTAL

Reagents

Trimetrexate and 2,4-diamino-5-methyl-6-[(4-chloroanilino)methyl]- 
quinazoline were obtained from Warner Lambert/Parke Davis (Ann Arbor, MI, U.S.A.). Methanol was purchased from Burdick and Jackson Labs. (Muskegon, MI, U.S.A.). Triethylamine $(99+\%$ purity) was purchased from Aldrich (Milwaukee, WI, U.S.A.). N-Methyl-N-trimethylsilyltrifluoroacetamide (MSTFA) was purchased from Pierce (Rockford, IL, U.S.A.). The $\mathrm{C}_{18}$ BondElut sample preparation columns, with a 500-mg capacity column bed, were purchased from Analytichem (Harbor City, CA, U.S.A.). A vacuum manifold with the capacity of holding ten sample preparation columns for simultaneous sample extractions was also purchased from Analytichem.

\section{Stock solutions}

A TMQ solution (2.71 $\mathrm{mM}$ in methanol) and a 2,4-diamino-5-methyl-6-[(4chloroanilino)methyl] quinazoline (internal standard, I.S.) solution (1.05 mM in methanol) were prepared and stored at $-30^{\circ} \mathrm{C}$.

\section{Standards}

The TMQ stock solution was diluted 1:100 with water to yield the TMQ standard solution No. 1 containing $0.027 \mathrm{mM}$ TMQ. TMQ standard solution No. 2 containing $0.27 \mathrm{mM}$ TMQ was prepared by diluting the TMQ stock solution 1:10 with water. The I.S. stock solution was diluted with water to yield the I.S. solution containing $0.105 \mathrm{mM}$ I.S. Standard TMQ and I.S. solutions were prepared from stock solutions immediately before use.

Quality-control (QC) samples at two concentrations $(0.27$ and $1.35 \mu M$ TMQ) were prepared by spiking blank plasma with the appropriate volumes of the TMQ standards. After mixing, 1.2-ml aliquots were transferred to polypropylene tubes, tightly capped, and stored frozen at $-30^{\circ} \mathrm{C}$. Three QC samples of each concentration were included with every group of experimental samples to be analyzed.

\section{GC-SIM-MS parameters}

The instrument used in these studies was a Hewlett-Packard Model 5987A gas chromatograph-mass spectrometer with electron-impact (EI) ionization and selected-ion monitoring. Temperature zones were set as follows: ion source temperature, $250^{\circ} \mathrm{C}$; analyzer temperature, $300^{\circ} \mathrm{C}$; transfer line temperature, $300^{\circ} \mathrm{C}$. The electron energy was set at $70 \mathrm{eV}$ and the multiplier voltage was $2400 \mathrm{~V}$. The mass ion at $\mathrm{m} / z 331$ was monitored from 1.0 to 4.2 min into the run.

Separation of the trimethylsilyl (TMS) derivatives of TMQ and I.S. was accomplished using a fused-silica capillary column ( $5 \mathrm{~m} \times 0.32 \mathrm{~mm}$ I.D.) coated with a cross-linked methyl silicone liquid phase $(0.17-\mathrm{mm}$ film thickness). Gas chromatographic conditions were: injection port and GC-MS interface oven temperatures were $300^{\circ} \mathrm{C}$; GC column oven temperature was programmed from $200^{\circ} \mathrm{C}(0.1 \mathrm{~min}$ hold $)$ at $15^{\circ} \mathrm{C} / \mathrm{min}$ to $300^{\circ} \mathrm{C}$; carrier gas (helium) flow-rate was set to $1.0 \mathrm{ml} / \mathrm{min}$.

Under these conditions the retention times of I.S. and TMQ were 2.8 and 3.7 min, respectively. 


\section{Sample preparation}

To $1.0 \mathrm{ml}$ plasma were added $1.05 \mathrm{nmol}$ I.S. $(10 \mu \mathrm{l}$ of the I.S. standard solution). The sample was vortexed and loaded onto a $\mathrm{C}_{18}$ Bond-Elut column which was prewet by aspirating two column reservoir volumes of methanol followed by two column reservoir volumes of water through the column. Only the excess water was pulled through the column before adding the sample. The columns were then washed with $6.0 \mathrm{ml}$. distilled water followed by $3.0 \mathrm{ml}$ methanol. To this point all eluates were discarded. Drug and I.S. were eluted from the column in $1.0 \mathrm{ml}$ methanol $-10 \%(\mathrm{v} / \mathrm{v})$ triethylamine (TEA). The methanol-TEA eluates were dried in a vacuum centrifuge heated to $45^{\circ} \mathrm{C}$.

Trimethylsilylation of TMQ and I.S. was accomplished using MSTFA. MSTFA $(50 \mu \mathrm{l})$ was added to the dried residue, the tubes were vortexed and incubated at room temperature for $15 \mathrm{~min}$. A volume $(0.5-2.0 \mu \mathrm{l})$ of the resulting derivatization solution was injected for GC-SIM-MS analysis.

\section{Standard calibration curve}

Blank plasma samples were spiked in duplicate with the appropriate volumes of the TMQ standard solutions Nos. 1 and 2 to concentrations ranging from 0.14 to $2.71 \mu M$ TMQ and subjected to the sample preparation procedure described above. Calibration curves were run (in duplicate) with each set of experimental samples.

\section{Calculations}

Calibration curves were constructed by plotting the ratio of the integrated peak area of TMQ to that of the internal standard as a function of the plasma TMQ concentration. The best-fit straight line was determined using a simple
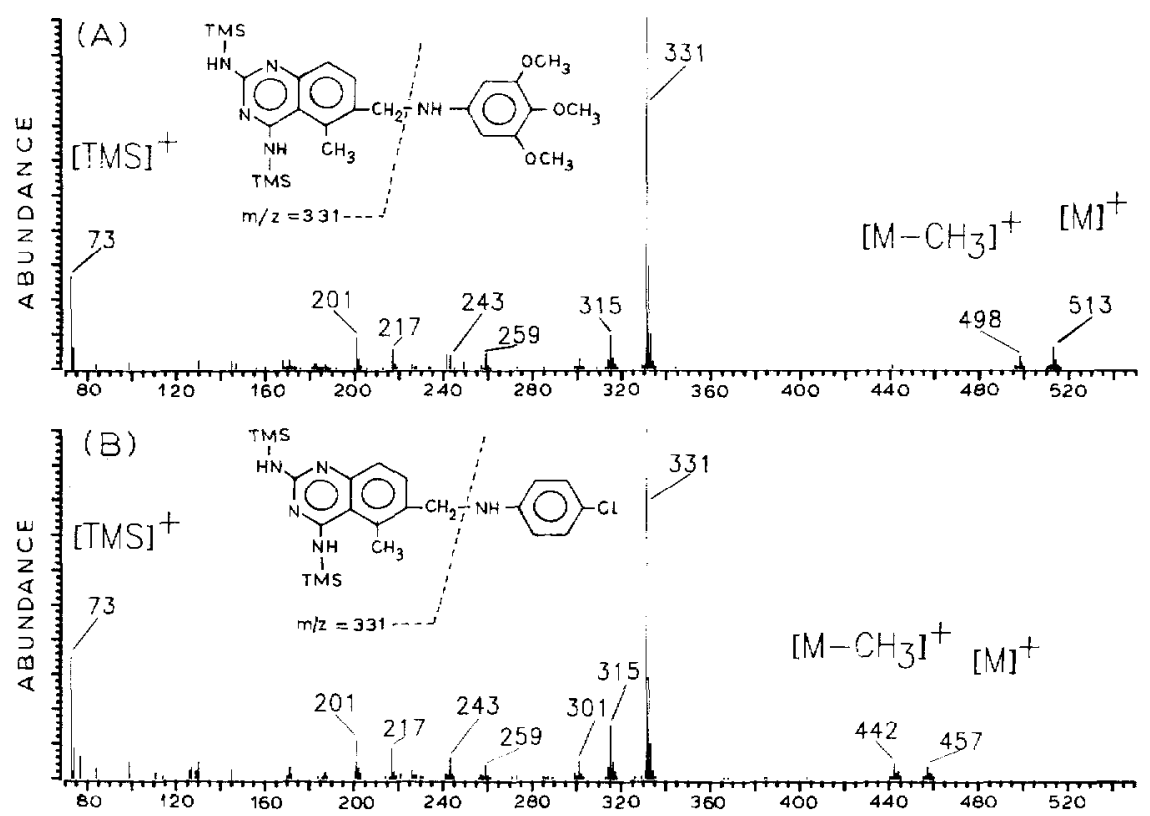

Fig. 1. Molecular structures and EI mass spectra of bis(TMS) derivatives of TMQ (A) and I.S. (B). 
linear regression of the $\ln$ (peak-height ratio) versus $\ln$ (concentration) data. The TMQ concentrations of unknown samples were calculated using the results of the regression analysis.

\section{RESULTS AND DISCUSSION}

The molecular structures and EI mass spectra of the TMS derivatives of TMQ and I.S. are shown in Fig. 1. Also indicated is the EI fragmentation pattern resulting in the identical mass ion of maximum abundance $(\mathrm{m} / \mathrm{z} 331)$ for both the TMQ and I.S. bis(TMS) derivatives. Since this mass ion is so overwhelmingly abundant in the mass spectra of TMQ and the I.S., little could be gained by monitoring any additional mass ions.

Figs. 2, 3 and 4 illustrate typical total-ion chromatograms from the GC-SIM-MS analyses of control (blank) human plasma with added internal standard (Fig. 2), a TMQ-spiked calibration sample containing $0.14 \mu M$ TMQ (Fig. 3) and a patient plasma sample containing $0.22 \mu M$ TMQ. The figure

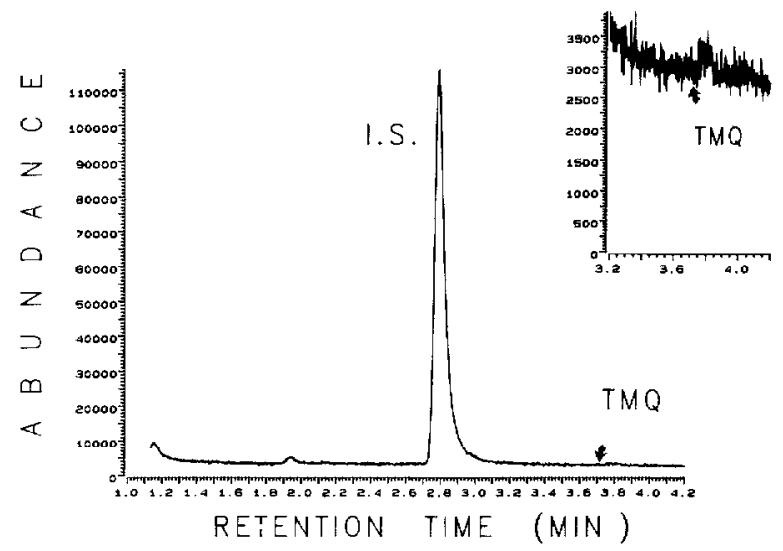

Fig. 2. Typical chromatogram of control (blank) human plasma with added internal standard. Insert shows the TMQ region of the chromatogram on an expanded scale.

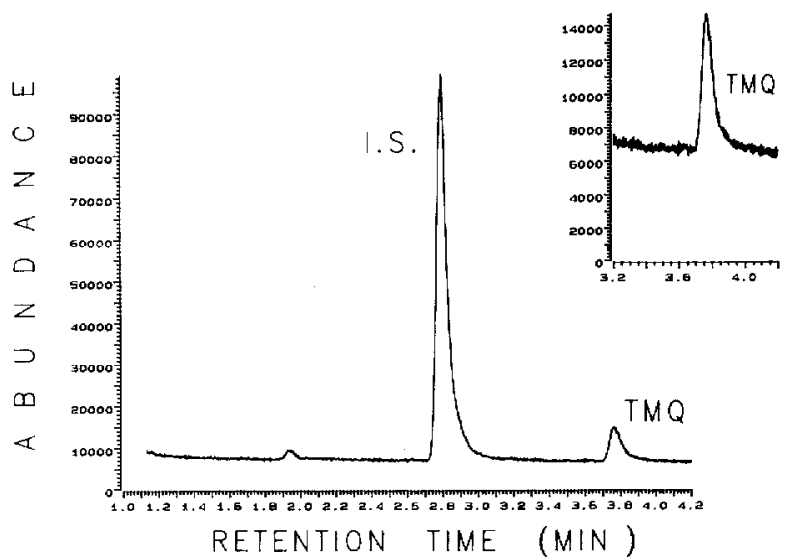

Fig. 3. Typical chromatogram of TMQ-spiked control human plasma at a concentration of $0.14 \mu M$ TMQ. Insert shows the TMQ region of the chromatogram on an expanded scale. 


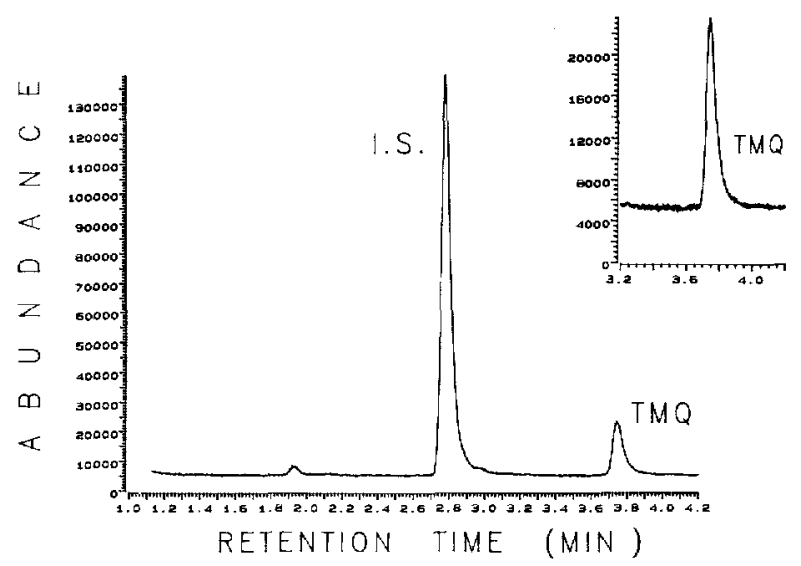

Fig. 4. Typical chromatogram of patient plasma containing $0.23 \mu M$ TMQ. Insert shows the TMQ region of the chromatogram on an expanded scale.

inserts depict with a greatly expanded scale the region of the chromatogram containing the TMQ peak. If the minimum detectable level is defined as three times the background signal noise, then from the insert of Fig. 2 one can estimate that under these conditions the minimum detectable level would be $0.005-0.014 \mu M$ TMQ. Throughout our clinical studies, no interfering peaks were present in the several hundred patient plasma samples assayed. The chromatographic analysis time for each sample was $4.2 \mathrm{~min}$, and this laboratory has routinely processed 50-100 samples in the normal 8-h working day.

The validity of the assay procedure was established through a careful study of the linearity of response, reproducibility, accuracy and precision. The peak-

\section{TABLE I}

\section{BACK-CALCULATED CONCENTRATIONS FOR TMQ STANDARDS}

Data were obtained through linear regression analysis of $\ln$ (peak-area ratio) versus $\ln$ (concentration) of added TMQ.

\begin{tabular}{llllllll}
\hline Day & \multicolumn{3}{l}{ Concentration $(\mu M)$} & & Slope & Intercept & $r$ \\
\cline { 2 - 5 } & 0.14 & 0.27 & 1.35 & 2.71 & & & \\
\hline 1 & 0.14 & 0.28 & 1.14 & 2.71 & 0.97 & -0.28 & 0.997 \\
& 0.13 & - & 1.39 & 3.02 & & & \\
2 & 0.17 & 0.24 & 1.32 & 2.79 & & & \\
& 0.13 & 0.26 & 1.39 & 2.85 & 0.98 & -0.37 & 0.999 \\
& 0.14 & 0.29 & 1.27 & 2.67 & & & \\
3 & 0.15 & 0.27 & 1.32 & 2.70 & & & \\
& 0.17 & 0.27 & 1.38 & 2.91 & 1.01 & -0.29 & 0.998 \\
& 0.14 & 0.25 & 1.33 & 2.76 & & & \\
$n$ & 0.13 & 0.27 & 1.32 & 2.57 & & & \\
$n$ & 9 & 8 & 9 & 9 & 3 & 3 & 3 \\
Mean & 0.14 & 0.27 & 1.32 & 2.78 & 0.99 & -0.31 & 0.998 \\
S.D. & 0.016 & 0.016 & 0.078 & 0.136 & 0.02 & 0.05 & 0.001 \\
C.V. (\%) & 11.4 & 5.9 & 5.9 & 4.9 & 2.0 & 16.1 & 0.1 \\
\hline
\end{tabular}


TABLE II

TRIMETREXATE CONCENTRATIONS IN SEEDED CONTROL SAMPLES ASSAYED OVER A THREE-DAY PERIOD

\begin{tabular}{lcc}
\hline Day & \multicolumn{2}{c}{ Trimetrexate concentration $(\mu M)$} \\
\cline { 2 - 3 } & $0.27 \mu M$ & $1.35 \mu M$ \\
\hline 1 & 0.27 & 1.30 \\
& 0.23 & 1.34 \\
& 0.23 & 1.39 \\
2 & 0.28 & 1.44 \\
& 0.26 & 1.45 \\
3 & 0.28 & 1.28 \\
& 0.26 & 1.28 \\
& 0.31 & 1.45 \\
Mean ( $\mu M$ ) & 0.24 & 1.28 \\
Standard deviation $(\mu M)$ & 0.26 & 1.36 \\
Coefficient of variation (\%) & 0.03 & 0.08 \\
Deviation from theoretical $(\%))$ & 10.1 & 5.6 \\
\hline
\end{tabular}

area ratio was directly proportional to the TMQ concentrations over the tested range of $0.07-2.71 \mu \mathrm{M}$. The best-fit lines were obtained using linear regression analysis of the $\mathrm{ln}$-transform data. To test the reproducibility of this procedure, calibration samples were prepared in triplicate on three successive days. The results of these studies are summarized in Table I. Triplicate $Q C$ samples at each concentration ( 0.27 and $1.35 \mu M$ TMQ) were run in parallel. The reproducibility of the daily standard curves had coefficients of variation which ranged between $11.4 \%$ (at lowest concentration) to $4.9 \%$ (at highest concentration).

The accuracy and precision of the method were assessed by seeding plasma at TMQ concentrations of 0.27 and $1.35 \mu M$. Triplicate QC samples at each concentration were assayed on each of three consecutive days. Table II summarizes these results. The assay precision was found to have coefficients of variation ranging from 5.6 to $10.1 \%$. The concentration means for the seeded control samples were found to be within -3.7 to $+0.7 \%$ of the theoretical values for TMQ.

Application of the method developed was demonstrated by measuring the steady-state plasma TMQ levels in a patient receiving each of two intravenous TMQ infusions (14.5 $\mu \mathrm{mol}$ TMQ per $40 \mathrm{~h}$ and $21.7 \mu \mathrm{mol}$ TMQ per $40 \mathrm{~h}$ ). Peripheral venous blood was sampled at $0,16,24$ and $40 \mathrm{~h}$ into the infusion. The steady-state venous plasma TMQ levels (mean \pm S.D.) attained during the two infusion rates were $0.16 \pm 0.02$ and $0.23 \pm 0.03 \mu M$ TMQ.

The GC-SIM-MS assay described here for plasma TMQ levels is sufficiently sensitive and accurate to be used in pharmacokinetic studies and therapeutic monitoring of this new non-classical antifolate. To date, the analysis of several hundred patient plasma samples, as well as blank plasma samples spiked with $1.0 \mu \mathrm{g} / \mathrm{ml}$ folic acid, methotrexate, $3^{\prime}, 5^{\prime}$-dichloroamethopterin or aminopterin, has failed to elicit any chromatographic interferences. Studies are presently 
underway to investigate necessary modifications to the procedure for applicability in the study of TMQ metabolism and its application to the determination of TMQ levels in tissues and biological fluids other than plasma.

\section{ACKNOWLEDGEMENT}

This work was supported, in part, by NIH Grant No. CA33825.

\section{REFERENCES}

1 E.F. Elslager and J. Davoll, in R.N. Castle and L.B. Townsend (Editors), Lectures in Heterocyclic Chemistry, Vol. II, Hetero Corp., Orem, UT, 1974, pp. 5-97.

2 J.J. McCormack, in W. Pfleiderer (Editor), Chemistry and Biology of Pteridines, Walter de Gruyter, New York, 1976, p. 125.

3 J.R. Bertino, W.L. Sawicki, B.A. Moroson, A.R. Cashmore and E.F. Elslager, Biochem. Pharmacol., 28 (1979) 1983.

4 H. Diddens, D. Niethammer and R.C. Jackson, Cancer Res., 43 (1983) 5286.

5 J.R. Bertino, Cancer Res., 39 (1979) 293.

6 T. Ohnoshi, T. Ohnuma, I. Takahashi, K. Scanlon, B.-A. Kamen and J.F. Holland, Cancer Res., 42 (1982) 1655.

7 G.F. Borsa and F.A. Whitmore, Cancer Res., 29 (1969) 737.

8 G.F. Borsa, F.A. Whitmore, F.A. Valeriote, D. Collins and W.R. Bruce, J. Natl. Cancer Inst. (U.S.), 42 (1969) 235.

9 H.E. Skipper, F.M. Schabel, L.B. Mellett, J.A. Montgomery, L.J. Wilkoff, H.H. Lloyd and R.W. Brockman, Cancer Chemother. Rep., 54 (1970) 431.

10 B.A. Chabner and R.C. Young, J. Clin. Invest., 52 (1973) 1804.

11 H.M. Pinedo, D.S. Zaharko, J.M. Bull and B.A. Chabner, Cancer Res., 37 (1977) 445.

12 D.S. Zaharko, Pharmacological Basis of Cancer Chemotherapy, Williams and Wilkins, Baltimore, MD, 1975, pp. 69-84.

13 F.M. Sirotnak, Pharmacol. Ther. Part A, 8 (1980) 71.

14 E.C. Weir, A.R. Cashmore, R.N. Freyer, M.L. Graham, N. Hsiao, W.L. Sawicki and J.R. Bertino, Cancer Res., 42 (1982) 1696.

15 J.J. McCormack, personal communication.

16 J.J. Heusner and J.J. McCormack, J. Pharm. Sci., 70 (1981) 827.

17 J.C. Drake, C.J. Allegra, G.A. Curt and B.A. Chabner, Cancer Treat. Rep., 69 (1985) 641 . 